\title{
Modified Universal Design Survey: Enhancing Operability of Launch Vehicle Ground Crew Worksites
}

\author{
Jennifer L. Blume* \\ Jacobs Engineering, Science, and Technical Services (ESTS) Group, Huntsville, Alabama, 35806
}

\begin{abstract}
Operability is a driving requirement for next generation space launch vehicles. Launch site ground operations include numerous operator tasks to prepare the vehicle for launch or to perform preflight maintenance. Ensuring that components requiring operator interaction at the launch site are designed for optimal human use is a high priority for operability. To promote operability, a Design Quality Evaluation Survey based on Universal Design framework was developed to support Human Factors Engineering (HFE) evaluation for NASA's launch vehicles. Universal Design per se is not a priority for launch vehicle processing however; applying principles of Universal Design will increase the probability of an error free and efficient design which promotes operability. The Design Quality Evaluation Survey incorporates and tailors the seven Universal Design Principles and adds new measures for Safety and Efficiency. Adapting an approach proven to measure Universal Design Performance in Product, each principle is associated with multiple performance measures which are rated with the degree to which the statement is true. The Design Quality Evaluation Survey was employed for several launch vehicle ground processing worksite analyses. The tool was found to be most useful for comparative judgments as opposed to an assessment of a single design option. It provided a useful piece of additional data when assessing possible operator interfaces or worksites for operability.
\end{abstract}

\section{Introduction}

$\mathbf{7}$ xperience with the Space Shuttle shows that designs which do not consider operability as an inherent system ב performance goal will be labor-intensive and thus very expensive to operate. ${ }^{1}$ Operability in this context is defined as the degree to which a design is safe and easy and thus inexpensive to operate. The Space Shuttle was designed with flight performance as its single design goal; processing and maintenance operations were not identified until after the design. ${ }^{2}$ Consequently, ground operations for the Space Shuttle requires extensive manual construction of custom scaffolding, platforms, ladders, and covers, custom components and component installation, and custom testing and calibration equipment. ${ }^{3}$ The operations as well as all of the special training and certification require a significant amount of time. Furthermore, research of Shuttle ground processing incidents, which can significantly impact processing time, indicates that $72 \%$ are attributable to "human error". ${ }^{4}$ Optimizing the design for human operation will reduce such incidents. As a result of numerous studies on Shuttle program costs, operability is now a key factor for the success of any future space launch vehicle.

This emphasis on operability was a driver of the most recent National Aeronautical Space Association (NASA) space exploration effort, the Constellation

Program. The Ares I vehicle of the Constellation Program was planned to be the launch vehicle that would send the next astronauts into space. After being assembled at the Launch Site, ground crew would perform numerous tasks to prepare the vehicle for launch. These tasks include visual inspections, cover removal, tank loading, arming, equipment calibration, and tests. In addition, failed components

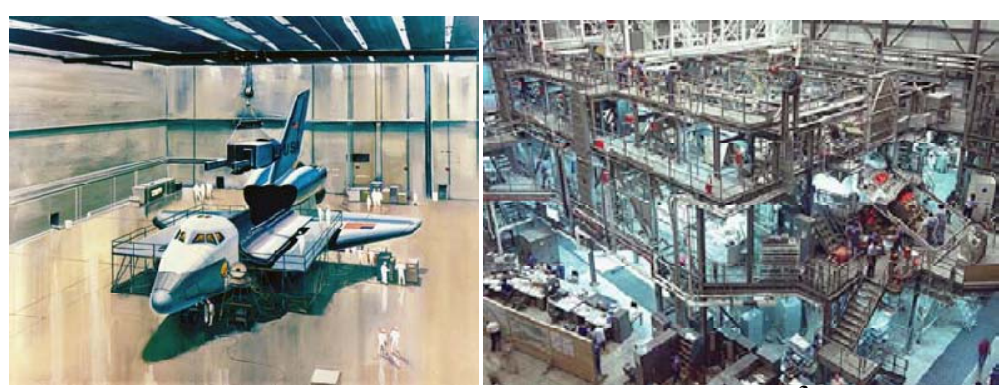

Figure 1. Shuttle Ground Processing Plans vs. Reality

\footnotetext{
* Sr. Human Factors Specialist, Space and Vehicle Systems and Mission Operations, 1525 Perimeter Parkway Suite 330, and AIAA Member.
} 
would have been replaced as time-critical ground maintenance tasks. To meet the Constellation goal for operability, it was imperative to optimize the design of vehicle hardware and equipment for safe, efficient, and effective human operation.

The Human Factors Engineering (HFE) team at NASA Marshall Space Flight Center (MSFC) uses various techniques for HFE analysis including computer modeling and simulation, human modeling, and mockups. The group developed a survey for use in assessments of conceptual designs based on the Universal Design approach. This survey was employed in several analyses to assist in Ares I design trades.

\section{Universal Design}

Universal Design is a framework to create products, places, and systems that can be used effectively by as many people as possible. ${ }^{5}$ The approach began with emphasis on special populations such as the elderly or people with disabilities or health conditions. This contrasted with typical design perspectives to design for the average or common user.

The contribution of Universal Design is not just the accommodation of the extreme ends of the population but in improving overall usability for the whole population. Universal Design per se is not a priority for launch vehicle processing which is a specialized skill requiring training and knowledge. However, applying principles of Universal Design will increase the probability of an error free and efficient design which will promote operability.

The Universal Design framework includes of seven Principles and associated Guidelines as shown in Figure 1. ${ }^{\dagger, \ddagger}$ The Principles and a set of Performance Measures and an approach for collecting assessments of products are used in product design and assessment. ${ }^{7,8}$

† The Principles of Universal Design were conceived and developed by The Center for Universal Design at North Carolina State University. Use or application of the Principles in any form by an individual or organization is separate and distinct from the Principles and does not constitute or imply acceptance or endorsement by The Center for Universal Design of the use or application.

‡ The Principles of Universal Design were compiled by advocates of universal design, listed here in alphabetical order: Bettye Rose Connell, Mike Jones, Ron Mace, Jim Mueller, Abir Mullick, Elaine Ostroff, Jon Sanford, Ed Steinfeld, Molly Story, and Gregg Vanderheiden.

\section{2}

American Institute of Aeronautics and Astronautics 


\section{Design Quality Evaluation Survey}

\section{A. Survey Measure Development}

The Design Quality Evaluation Survey developed for this space launch vehicle ground operations application is based on the Universal Design Principles, Guidelines, and Performance Measures for Products. ${ }^{6,8}$ The Universal Design Principles, Guidelines and Performance Measures were tailored to be more relevant to a specialized space

\begin{tabular}{|c|c|}
\hline \multicolumn{2}{|c|}{ EQUITABLEUSE } \\
\hline $\begin{array}{l}\text { Provide the same means of use for all users; identical whenever } \\
\text { possible; equivalent when not. }\end{array}$ & $\begin{array}{l}\text { All potential operators could use this design in essentially the same way, regardless } \\
\text { of differences in personal capabilities. }\end{array}$ \\
\hline \multicolumn{2}{|c|}{ REXIBITY INUSE } \\
\hline Provide choice in methods of use. & Every potential operator can find at least one way to use this design effectively. \\
\hline Accommodate right- or left-handed access and use. & This design can be used with either the right or left had alone. \\
\hline Facilitate the user's accuracy and precision. & This design facilitates (or does not require) operator accuracy and precision. \\
\hline Provide adaptability to the user's pace. & This design can be used at whatever pace (quickly or slowly) the operator prefers. \\
\hline \multicolumn{2}{|c|}{ SIMPLE/ INTUITIVE } \\
\hline Eliminate unnecessary complexity. & This design is as simple and straightforward as it can be. \\
\hline Be consistent with user expectations and intuition. & An untrained person could use this design without instructions. \\
\hline Accommodate a wide range of literacy and language skills. & Any operator can understand the language used in this design. \\
\hline Arrange information consistent with its importance. & The most important features of this design are the most obvious. \\
\hline $\begin{array}{l}\text { Provide effective prompting and feedback during and after task } \\
\text { completion. }\end{array}$ & This design provides feedback to the user. \\
\hline Provide design that is operable with minimal \# of tools & This design requires a minimal number of tools. \\
\hline $\begin{array}{l}\text { Provide design that is operable with simple tools and simple tool } \\
\text { configurations }\end{array}$ & The tools for this design are easy to use. \\
\hline \multicolumn{2}{|c|}{$\begin{array}{ll} & \text { PERCEPTABLE INFORMATION } \\
\end{array}$} \\
\hline $\begin{array}{l}\text { Use different modes (pictorial, verbal, tactile) for redundant } \\
\text { presentation of essential information. }\end{array}$ & This design can be used without hearing. \\
\hline $\begin{array}{l}\text { Differentiate elements in ways that can be described (i.e., make it easy } \\
\text { to give instructions or directions). }\end{array}$ & The features of this design can be clearly described in words. \\
\hline Provide labeling that supports identification and operation of the design & This design has all of the labels needed to use the design. \\
\hline \multicolumn{2}{|c|}{$\begin{array}{ll} & \text { TOLERANCE FORERROR } \\
\end{array}$} \\
\hline $\begin{array}{l}\text { Arrange elements to minimize hazards and errors: most used elements, } \\
\text { most accessible; hazardous elements eliminated, isolated, or shielded. }\end{array}$ & Hazardous elements are isolate or shielded. \\
\hline Provide warnings of hazards and errors. & This design draws the operators' attention to errors or hazards. \\
\hline Provide fail safe features. & $\begin{array}{l}\text { If the operator makes a mistake with this product, it won't cause damage or injure the } \\
\text { operator. }\end{array}$ \\
\hline Discourage unconscious action in tasks that require vigilance. & This design prompts the user to pay attention during critical tasks. \\
\hline \multicolumn{2}{|c|}{ LOWPHYSICALEFORT } \\
\hline Allow user to maintain a neutral body position. & This design can be used comfortably (e.g., without awkward movements or postures). \\
\hline Use reasonable operating forces. & This design can be used by someone who is weak or tired. \\
\hline Minimize repetitive actions. & $\begin{array}{l}\text { This design can be used without repeating any motion enough to cause fatigue or } \\
\text { pain. }\end{array}$ \\
\hline Minimize sustained physical effort. & This design can be used without having to rest afterward. \\
\hline \multicolumn{2}{|c|}{$\begin{array}{ll}\text { SIZE AND SPACEFOR APPROACH ANDUSE } \\
\end{array}$} \\
\hline $\begin{array}{l}\text { Provide a clear line of sight to important elements for any seated or } \\
\text { standing user. }\end{array}$ & $\begin{array}{l}\text { It is easy for a operator of any size to see all the important elements of this design } \\
\text { from any reasonable position }\end{array}$ \\
\hline $\begin{array}{l}\text { Make reach to all components comfortable for any seated or standing } \\
\text { user. }\end{array}$ & $\begin{array}{l}\text { It is easy for a operator of any size to reach all the important elements of this design } \\
\text { from any reasonable position }\end{array}$ \\
\hline Accommodate variations in hand and grip size. & This design can be used by an operator with hands of any size. \\
\hline clearance - Provide adequate space for the use & There is enough space to use this design with devices or assistance \\
\hline access - Ability and means to enter and approach & It is easy to approach the design \\
\hline \multicolumn{2}{|r|}{ SAFETY } \\
\hline Provide a design that is safe to use & This design is safe to use \\
\hline Provide a design that minimizes risk to the operator & This design minimizes risk to he operator \\
\hline Minimize risk to the system & This design minimizes risk to the system \\
\hline \multicolumn{2}{|r|}{ EPCAENCY } \\
\hline Provide a design that requires as few operators as possible & This design requires a minimal number of operators \\
\hline $\begin{array}{l}\text { Provide a design that can achieve the desired goal in the fewest } \\
\text { actions possible }\end{array}$ & This design requires a minimal number of actions to operate \\
\hline $\begin{array}{l}\text { Provide a design that requires the least amount of tools and extra } \\
\text { equipment as possible }\end{array}$ & This design requires a minimum support equipment and tools to use \\
\hline
\end{tabular}

Figure 3. Survey Principles (grey box), Detailed Principles (left column) and the Associated Evaluation Criteria (right column). 
vehicle ground processing environment. Additional principles and associated guidelines and measures were generated to reflect agency priorities or heritage assessment perspectives. The resulting set of measures shown in Fig 3 consists of principles (7 original Universal Design principles and two new principles), detailed principles (derived and tailored from the Universal Design Guidelines), and evaluation criteria statements for each detailed principle (derived and tailored from the Universal Design Product Performance Measures). The evaluation criteria are the statements that are used directly to analyze design concepts.

The Universal Design Equitable Use Principle is not as relevant to this application as it is to consumer products or architecture. Space vehicle processing is a specialized and professional field for which perceptions of equitable access and utility are not as applicable. The Equitable Use Principle was included because the population of ground operators is varied; ensuring that a design is usable across the widest range of operators not only enhances the operation of the design but also supports optimal ground operations execution and logistics. Only a single measure is included for this principle as opposed to the four measures in the Universal Design Performance of Products evaluation approach.

The following Universal Design Principles and associated Guidelines and Performance Measures were tailored only with modified wording: Flexibility, Tolerance for Error, Low Physical Effort.

For the Simple/Intuitive Principle, the Guidelines and Performance Measures were tailored only with modified wording. In addition, two new detailed principles and evaluation criteria were added to address issues with quantity and usability of tools. Launch vehicle processing involves the use of many tools and this is a concern for HFE and operability.

The Information Principle was tailored by removing the detailed principles for sightless operation and by adding a detailed principle and evaluation criteria for labeling.

A new detailed principle with evaluation criteria was added to the Size and Space Principle to focus assessment on accessibility and clear volume for body and equipment movement and manipulation.

A principle associated with Safety was developed to reflect assessment of risk to the operator and risk to the equipment and mission due to worksite or hardware design flaws. Damage to flight hardware during ground processing can have serious impacts to flight processing schedule and launch window availability. Undetected damage can result in performance failures during flight.

A final principle for Efficiency was developed to uncover potential impacts to processing time as a consequence of design. Any impacts to processing time impacts operational cost.

\section{B. Survey Tool}

The survey is intended to be completed by participants, or "users", or by HFE personnel conducting an assessment. The survey presents the evaluation criteria, all phrased in the form of a positive statement about the design, and a selection of 6 judgments to reflect degree of agreement with the statement (Strongly Agree, Agree, Neutral, Disagree, Strongly Disagree) as well as a judgment of "Not Applicable". All statements are phrased in the utmost positive, or the design goal, so that the degree to which judgments tend toward "completely agree" directly reflects the degree to which the design is good. After the Survey is completed, the data can be visualized and organized in different patterns by detailed principles and principles.

\section{Case Studies}

The Design Quality Evaluation Survey was employed for several analyses of Ares I ground processing worksites. For each analysis the survey was tailored slightly to reflect constraints in the particular task or worksite being evaluated. The analyses are described here only in terms that are necessary to illustrate the
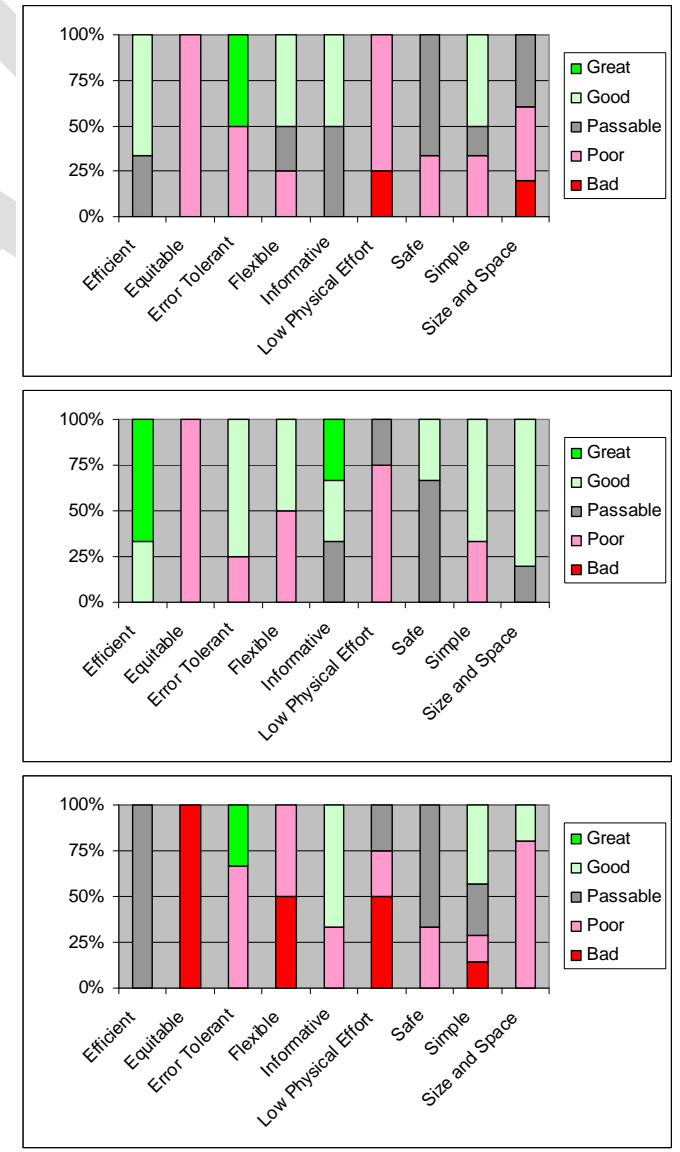

Figure 4. Fueling worksite survey results showing judgments for the small (top), large (middle), and left-handed participant (bottom). 
utility of the survey; the following sections are not intended to present details or findings for the actual analyses

\section{A. Fueling Worksite Evaluation}

One HFE analysis evaluated an Ares I fuel service panel design, configuration, and installation for human operation. At the time of the evaluation the service panel, which is a part of the flight vehicle rather than a piece of non-flight ground support equipment, was mounted inside the vehicle near the access opening. The operator would utilize the service and manual valves on the service panel during fuel fill operations. The operator would stand on a platform outside the vehicle and lean in through the access opening. Because one of the fuels is hazardous, protective suits may be required depending on the final design of the valve and assessment by Safety panels.

A mockup of the worksite was constructed at the George C. Marshall Space Flight Center's (MSFC's) Performance Analysis and Development Demonstrator (PADD) facility ${ }^{\S}$. A large and a small participant, reflecting a stature measurement of a $95^{\text {th }}$ and a $5^{\text {th }}$ percentile, respectively, and a left-handed participant completed a simulated procedure of loading fuel. After performing the simulated procedure, each participant completed the survey independently. The participants had no problems interpreting the survey's statements or deciding how it should be completed. All participants made liberal use of the comments section.

The Survey results can be visualized in a number of different ways. In Fig 4 you can see graphs that reflect the degree to which the design is considered acceptable for the small participant (top of the figure), the large participant, and the left-handed participant (bottom of the figure). Cursory inspections of the red and green coding shows that the design was very difficult and less suited to the left handed operator and that the design was most effective for the larger operator. These results harmonized with verbal data provided during the exercise as well as with notes from independent observers. As a result of this analysis, the service panel was reoriented and resized and the valves were relocated to improve access.

\section{B. Internal Platform Evaluation}

This HFE analysis evaluated different access platform designs for a cable connection task and some ordnance loading and securing tasks. A mockup of the connection hardware and the vehicle access opening and internal structure was constructed at the NASA MSFC PADD facility. A large and small participant, reflecting stature measurements of a $95^{\text {th }}$ and a $5^{\text {th }}$ percentile, respectively, completed the cable connector mating task and the ordnance loading and securing tasks with three different operator access platform configurations. The first was the Reach In configuration; the operator stands outside the vehicle and reaches through the access opening to perform the tasks. The second was a Diving Board configuration; the operator stands just inside the access opening on a Diving Board platform that is mounted outside the vehicle and across the access opening threshold. This put the operator inside the vehicle but constrained the operator to position of the diving board. The final configuration was the Extended Access configuration; the operator stands inside the vehicle on platforms that are mounted inside the vehicle and are slightly wider than the access opening.

Graphs of survey results shown in Fig. 5 clearly illustrated both the difference in ease of task performance across access platform configurations and between participants' sizes. These results mirrored the reported and observed performance of the tasks during the simulation. This analysis resulting in an operational constraint extended internal platforms installation for cable connection and ordnance loading and securing tasks regardless of the hardware's proximity to the access hatch. In addition, some equipment was relocated and reoriented to improve access from just inside the access opening.
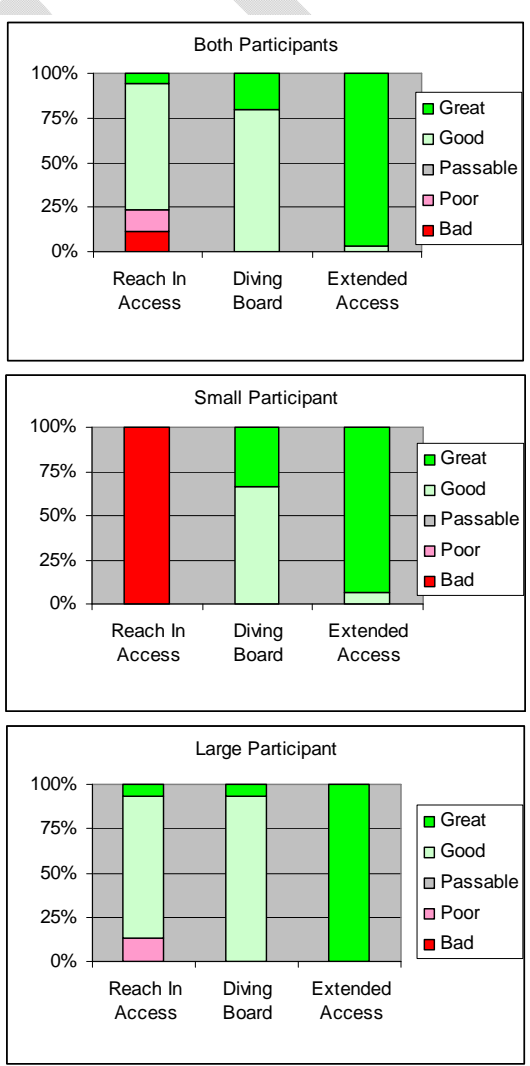

Figure 5. Access platform survey results showing judgments collapsed across participants (top), only the small participant (middle), and only the large participant (bottom).

\footnotetext{
§ For more information on MSFC's PADD facility, please contact David Reynolds, MSFC, HUNTSVILLE, AL, 35812, USA 256.544.4579
} 


\section{Conclusion}

The Design Quality Evaluation Survey was useful both for assessment of a single design as well as for comparison of multiple designs. Although the test cases described herein used the survey primarily to compare two or more design options, the principle categories and subcategories can be used to target specific performance issues and focus redesign efforts more efficiently. In addition, the survey was demonstrated in the context of a mockup exercise; however, it can add value to HFE assessments of drawings or computer models as well.

While the survey results tended to mirror participant comments and/or observers notes, those tend to be narrative. In NASA's engineering community, it was useful to have a numerical means of reflecting those narrative findings. The ability to quickly create visualizations of design strengths and weaknesses was very helpful in communications with program managers and design engineers.

Future work with the survey will include a review of the detailed principles and evaluation criteria for the two new principles of Safety and Efficiency.

The primary design driver for space launch vehicle is flight performance. They are rockets; they are not offices, laboratories, or manufacture floors. However, studies have shown that space launch and flight vehicles that are not optimized for human ground operator tasks are too costly. The use of HFE methods and surveys are necessary to support operability of all future space launch vehicles.

\section{Appendix}

Shown here is the Design Quality Evaluation Survey. This survey was tailored further for each case study discussed herein.

\begin{tabular}{|l|l|l|l|l|l|}
\hline Evaluation criterion & & & & \\
\hline $\begin{array}{l}\text { All potential operators could use this } \\
\text { design in essentially the same way. } \\
\text { regardless of differences in personal } \\
\text { capabilities. }\end{array}$ & & & & & \\
\hline $\begin{array}{l}\text { Every potential operator can find at least } \\
\text { one way to use this design effectively. }\end{array}$ & & & & \\
\hline $\begin{array}{l}\text { This design can be used with either the } \\
\text { right or left hand alone. }\end{array}$ & & & & & \\
\hline $\begin{array}{l}\text { This design facilates (or does not } \\
\text { require) operator accuracy and } \\
\text { precision. }\end{array}$ & & & & \\
\hline $\begin{array}{l}\text { This design can be used at whatever } \\
\text { pace (quicky or siowly) the operator } \\
\text { prefers. }\end{array}$ & & & & \\
\hline $\begin{array}{l}\text { This design is as simple and } \\
\text { straightforward as it can be. }\end{array}$ & & & & \\
\hline $\begin{array}{l}\text { An untrained person could use this } \\
\text { design without instructions. }\end{array}$ & & & & \\
\hline $\begin{array}{l}\text { Any operator can understand the } \\
\text { language used in this design. }\end{array}$ & & & & \\
\hline $\begin{array}{l}\text { The most important features of this } \\
\text { design are the most obvious. }\end{array}$ & & & & \\
\hline $\begin{array}{l}\text { This design provides feedback to the } \\
\text { user. }\end{array}$ & & & & \\
\hline $\begin{array}{l}\text { This design requires a minimal number } \\
\text { of tools }\end{array}$ & & & & \\
\hline The tools for this design are easy to use & & & & \\
\hline $\begin{array}{l}\text { This design can be used without } \\
\text { hearing. }\end{array}$ & & & & & \\
\hline $\begin{array}{l}\text { The features of this design can be } \\
\text { clearly described in words }\end{array}$ & & & & & \\
\hline $\begin{array}{l}\text { This design has all of the labels needed } \\
\text { to use the design }\end{array}$ & & & & \\
\hline $\begin{array}{l}\text { Hazardous elements are isolated or } \\
\text { shielded }\end{array}$ & & & & & \\
\hline $\begin{array}{l}\text { This design draws the operators' } \\
\text { attention to errors or hazards. }\end{array}$ & & & & & \\
\hline $\begin{array}{l}\text { If the operator makes a mistake with this } \\
\text { product, it wont cause damage or injure } \\
\text { the operattor. }\end{array}$ & & & & \\
\hline
\end{tabular}

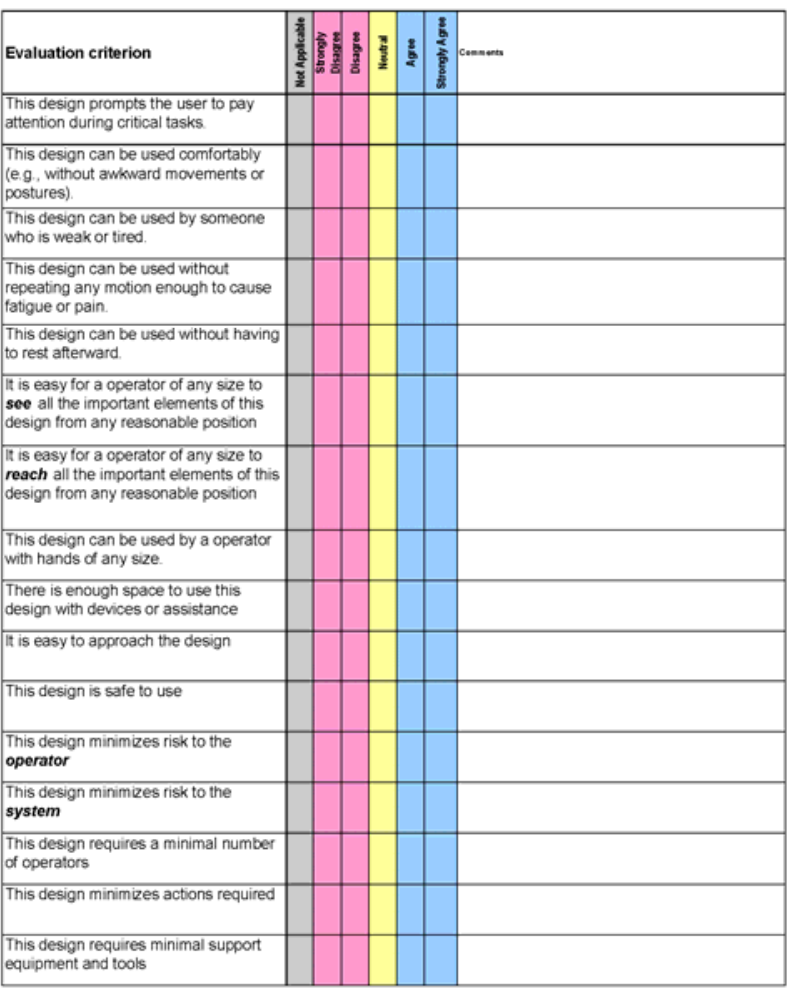

\section{Acknowledgments}

J. L. Blume thanks Jason Quick for the introduction to the discipline and practice of Universal Design. 


\section{References}

${ }^{1}$ Singer, C. E, Dumbacher, D. L., Lyles, G. M., Onken, J. F., "NASA's Ares I and Ares V Launch Vehicles Effective Space Operations Through Efficient Ground Operations,” SpaceOps 2008 Conference, CP3563, AIAA.

${ }^{2}$ Stambolian, D. B., Greenfield, T., "Spaceport 1-G Human Factors for Optimal Space Transportation System Design," Kennedy Space Center, Florida, USA: Kennedy Space Center, National Aeronautics and Space Administration.

${ }^{3}$ McClesky, C. Guidi, C., Brown, K., "Potential Strategies for Spaceport Systems Towards Airport-like Operations,” $2^{\text {nd }}$ Responsible Space Conference, CP6003, AIAA.

${ }^{4}$ Kanki, B. G., Blankmann, D. M. "Human Factors in Aerospace Maintenance Perspectives from NASA Research and Operations," Proceedings of for the $12^{\text {th }}$ Symposium on Human Factors in Aviation Maintenance, London, 1998.

${ }^{5}$ Mace, R. L., Hardie, G. J., Place, J. P., “Accessible Environments: Toward Universal Design” Design Intervention: Toward a More Humane Architecture, edited by W. E. Preiser, J. C. Vischer, and E. T. Van Nostrand Reinhold, NY, 1991.

${ }^{6}$ The Center for Universal Design. The Principles of Universal Design, Version 2.0. Raleigh, NC: North Carolina State University, 1997.

${ }^{7}$ Beecher, V. and Paquet, V. "Survey instrument for the universal design of consumer products," Applied Ergonomics, Vol. 36, 2005, pp. 363 - 372.

${ }^{8}$ The Center for Universal Design. Evaluating the universal Design Performance of Products. Raleigh, NC: North Carolina State University, 2000. 